\title{
Attitudes and Perspectives of First Year Medical Students Towards A Six Day Foundation Course
}

\author{
Ray, A. $^{1}$, Kumar, ${ }^{2}{ }^{2}$, Prathima, M. $^{3}$
}

\begin{abstract}
Introduction: The importance of orientation courses for medical entrants cannot be over emphasized and research in this area of medical education would help improve these courses and bring about effectiveness as well as some degree of universality in their content, duration and implementation. This paper was written with the aim of bringing to light the salient features of a course conducted at our institute and the feedback of students regarding the programme.
\end{abstract}

Methods: We conducted a six-week orientation course for new entrants. This course included sessions on Basic Life Support, Medical Literature Search, Early Clinical Exposure and Communication Skills. Pre and post course attitudes for these four domains were measured and compared by noting the participants' agreement with a predefined set of statements using a Likert's scale.

Results: One-hundred-and-eight students out of a total of 120 responded to our questionnaire. There was a significant improvement $(p<0.05)$ in the attitude scores for all four domains. Using Cronbach's alpha we found good reliability for these attitude scores.

Conclusion: We conclude that the course had a positive impact on the new entrants as it resulted in a significant improvement in their attitude scores in all the domains selected in our study. The description of the course could serve as a sample for designing more such courses with changes suited to individual institutions. In the future we aim to have focused group discussions and in depth interviews with students and faculty as a means of triangulation and to help improve the course in our own institute.

Keywords: Basic Life Support (BLS), Medical literature Search (MLS), Early Clinical Exposure (ECE), Communication Skills (CS)

\section{Introduction}

Joining medical college as a freshman is a major transition period involving a lot of adjustment. Conducting prior orientation courses before commencement of the actual study process goes a long way in helping the students adjust better to the new and often daunting environment in medical schools (Finkelstein et al, 2007; Kiessling et al, 2004; Moffat et al, 2004; Rosal et al, 1997).

${ }^{1}$ Associate Professor, Department of Obstetrics and Gynecology, Srinivas Institute of Medical Sciences and Research, Mangalore, India.

${ }^{2}$ Professor, Department of Obstetrics and Gynecology, Srinivas Institute of Medical Sciences and Research, Mangalore, India

${ }^{3}$ Department of Community Medicine, Srinivas Institute of Medical sciences and Research, Mangalore, India

Corresponding Author:

Amita Ray, Associate Professor, Department of Obstetrics and Gynecology, Srinivas Institute of Medical Sciences and Research, Mangalore, India.

Email: amitarays@gmail.com
About a third of US (Chumley et al., 2005; Russel, 2002) and two thirds of Canadian (Hendelman \& Byszewski, 2007) medical schools conduct such orientation courses at various transition levels of the medical undergraduate course which are popularly called White Coat Ceremonies (WCC). However, current literature reveals very little research interest in the design and impact of such orientation activities (Ellaway et al., 2014). The Medical Council of India, which is in the process of implementing new regulations to create a competent medical graduate, has proposed a restructured medical curriculum in its document "Vision 2015" (Medical Council of India, 2011 \& 2012).

Besides other proposals, it has advised the introduction of a 2 month foundation course for medical college entrants. Before this and subsequent to this, several Indian medical colleges have been and are conducting brief orientation courses for their medical undergraduates. However, there is no universal practice as regards to the content, duration and 
implementation of orientation courses and compared to the West there has been very little research on their design and impact (Mittal et al., 2014; Pandya, 2009).

This paper was written with the aim of bringing to light the salient features of a foundation course conducted at our institute and the feedback of students regarding the program. By this we hope to build a platform to generate research interest in the design and impact of such courses. The importance of orientation courses for medical entrants cannot be over emphasized and research in this area of medical education would help improve these courses and bring about effectiveness as well as some degree of universality in their content, duration and implementation.

Our specific objectives were,

a) To describe the foundation course conducted at our institute

b) To compare student attitudes towards selected topics or domains before and after the foundation course

c) To assess student perceptions about the overall effectiveness of the course

d) To describe suggestions for further improvement

\section{Methods}

\section{Study setting}

Srinivas Institute of Medical Sciences and Research Centre (SIMS\&RC) is a medical college situated in a semi-rural area in the outskirts of the city of Mangalore in the state of Karnataka in South India. It is affiliated to the Rajiv Gandhi University of Health Sciences (RGUHS) in Bangalore, the capital of the state of Karnataka. The students come from all over India. The MBBS course consists of four and a half years of medical school followed by one year of compulsory internship.

\section{Ethical Approval}

Ethical approval was sought and obtained from the Institutional Ethical Committee. It was decided that attending the course would not be made mandatory and any questionnaire administered would be done after obtaining consent from the participants.

\section{Participants and Groups}

The yearly intake of our institute is 150 , out of which 120 students enrolled for the course and 108 consented to take part in the study by answering the questionnaire. They ranged in age from 18 to 21 years. Of those that enrolled for the course, there were 75 males and 45 females. Majority did not speak English as their first language $(n=110)$. Kannada was the first language for the majority of students $(n=50)$. Besides this, other languages were those spoken in the neighbouring states of Karnataka. Written and spoken Hindi - the national language - was also understood by the majority of students. The questionnaire was prepared in English and translated to Hindi and Kannada.

\section{Content of the course}

The Department of Medical Education held a meeting to decide the content of the course, the speakers and facilitators for each topic and the manner in which the content would be conveyed to the students. The sessions were divided into three types depending on content.

A: Sessions specific to the institution and the curriculum

- Introduction to the staff and faculty

- An overview of the MBBS curriculum

- The geography of the land

- The health concerns of the surrounding community

- The alternative sources of medicine prevalent in this particular area

B: Sessions related to soft skills needed by all medical graduates

- Medical Literature Search (MLS)

- Communication Skills (CS)

- $\quad$ Basic Life Supports (BLS)

C: Sessions chiefly meant for relaxation and increasing interaction between the new entrants

- Ice breaking sessions

\section{Conduct of the course}

The course was conducted from 19th to the 24th of August 2013. Each of the six days were divided into a morning and afternoon section. Each of the six morning sections constituted 4 sessions of $30-40$ minutes duration covering the specified topics (A \& B). Students were given time to ask questions and at the end of each session one of them was asked to summarize their learning. While conducting sessions on the above topics, faculty tried to make it as interactive and student centered as possible. Various methods used for this purpose were

1. Question answer sessions:

- End of session summarization by participants

- Quizzes for participants before and after the sessions 


\section{Simulation using mannequins for BLS}

3. Role Plays for CS

- Role play for breaking bad news

- Role play for taking consent for surgery

- Role play for counselling for family planning practices

4. Hands on internet searching in the e-library for MLS

For the 6 afternoon sections, 120 students were divided by lottery into two groups of 60 each. One group went for community visits and the other group attended ice breaking sessions. Each group had three community visits and three ice breaking sessions.

Ice breaking sessions: Each group of 60 was further divided into 3 groups of 20 each. Each of the three groups had two senior students and a faculty member to conduct the ice-breaking sessions which involved group activities with the purpose of encouraging interaction both within and between groups. Each group was given a fun task and for every task they were encouraged to choose a leader who would organize and effectively conclude the task. This was done with the intention of fostering confidence and leadership skills.

Early Clinical Exposure (ECE): Three afternoon sessions were devoted to community visits as a part of early clinical exposure.

One visit, organized by the Peadiatrics Department was to a neighboring school where the children were being immunized as per the National Immunization Schedule. This program was being jointly run by the government agencies and the Peadiatric Department of the Institute. A second visit was to "Prashanthi Nilayam", a geriatric nursing home. This visit was organized by the Department of Medicine which regularly visited and was responsible for the health needs of this geriatric community. The third visit was to a Leprosy Rehabilitation Centre organized by missionaries running this centre and who were aided by the physicians and physiotherapists of our institute.

\section{Questionnaire}

We selected the topics in section B (CS, MLS, BLS) and Early Clinical Exposure (ECE) to compare student attitudes before and after the course as it was felt that these topics were relevant to every medical undergraduate. We did not include all the topics covered in the Foundation Course for fear of the questionnaire becoming too long resulting in student noncompliance. We decided to use our own questionnaire or set of statements. We felt that by doing so we would be able to better translate them into the languages that the students understood well and would be able to answer adequately. Four sets of statements were prepared by the Medical Education Unit for each of the four domains of ECE, CS, MLS, and BLS. A retro pre-approach was used to judge the change in attitudes. Attitudes were measured by noting the participants' agreement with the set of statements using a Likert scale. The scoring system adopted was: 5 - strongly agree with the statement, 4 agree, 3 - neutral, 2 - disagree and 1 - strongly disagree with the statement. None of the statements were negatively worded. The set of statements were prepared in English and then translated to Kannada (the state language) and Hindi (the national language). All four sets of statements were pretested on a group of third year students.

At the end of the questionnaire we added four close ended questions:

- Did this course allay your fears of a new environment?

- Did it help build your confidence?

- Did it familiarize you with the seniors and the faculty?

- Should such foundation courses be conducted as a routine in every medical college?

The last section in each questionnaire was a comments section in which the students were asked to give their suggestion to improve the course and make it more relevant.

\section{Data Analysis}

Data was analyzed using SPSS version 16.0. The four domains of Basic Life Supports (BLS), Communication Skills (CS), Early Clinical Exposure (ECE) and Medical Literature Search (MLS) were analyzed separately for change in attitude scores.

Basic Life supports had 6 statements to which each participant responded on a Likert scale. If helshe strongly disagreed with the statement the score was 1 , disagreed 2 , neutral 3 , agreed 4 and strongly agreed 5 . The median score of the participants for each statement was calculated. The median scores for all the statements were added to get a composite median pre-course score for this domain (BLS). The whole of this procedure was done for the post course scores to obtain a composite median post-course score. The same calculation was followed for Communication Skills which had 8 statements, Early Clinical Exposure which had 7 statements and Medical 
Literature Search which had 7 statements. As none of the statements were negatively worded, we did not have to reverse the scores for analysis. The data was normally distributed, so we used the paired t test to compare the sum change in attitude and elicit whether there was any significant $(p<0.05)$ difference for each of the four domains.

Cronbach's alpha for reliability was calculated for the attitude scores in each domain. The responses to the close ended questions and the suggestions for improvement were dealt with in a descriptive manner.

\section{Results}

One-hundred-and-eight students out of a total of 120 responded. Table 1 shows the median attitudes pre- and post-course towards BLS. There was a significant improvement in the attitude score $(p<0.05)$. Cronbach's alpha for calculating reliability was 0.852 for attitude scores towards BLS which indicated good reliability. Table 2 shows the median attitudes pre- and post-course towards CS. There was a significant improvement in the attitude score $(p<0.05)$. Cronbach's alpha for calculating reliability was 0.802 for attitude scores towards CS which indicated good reliability.

Table 1: Median attitude scores towards BLS pre and post Foundation Course at SIMS \& RC, Mangalore, Karnataka, India August 2013

\begin{tabular}{|c|c|c|}
\hline \multirow{2}{*}{$\begin{array}{l}\text { Statements to which response was generated } \\
\text { on a Likert's scale }\end{array}$} & \multicolumn{2}{|c|}{ Median } \\
\hline & Pre & Post \\
\hline Learning BLS skills is interesting & 3 & 4 \\
\hline $\begin{array}{l}\text { Learning BLS is an essential component of medical } \\
\text { education }\end{array}$ & 3 & 4 \\
\hline $\begin{array}{l}\text { Learning BLS builds my confidence in dealing with } \\
\text { critical situations }\end{array}$ & 3 & 4 \\
\hline $\begin{array}{l}\text { Non medical personnel should also be trained in } \\
\text { BLS skills to save more lives }\end{array}$ & 3 & 5 \\
\hline $\begin{array}{l}\text { BLS should be made a compulsory part of } \\
\text { undergraduate medical curriculum }\end{array}$ & 3 & 4 \\
\hline $\begin{array}{l}\text { Trained properly I would not hesitate to administer } \\
\text { BLS to a person in need }\end{array}$ & 3 & 4 \\
\hline Composite BLS score* & 18 & 25 \\
\hline
\end{tabular}

Table 2: Median Attitude scores towards CS pre and post Foundation Course at SIMS \& RC Mangalore, Karnataka, India August 2013

\begin{tabular}{|c|c|c|}
\hline \multirow{2}{*}{$\begin{array}{l}\text { Statements to which response was generated on a } \\
\text { Likert's scale }\end{array}$} & \multicolumn{2}{|c|}{ Median } \\
\hline & Pre & Post \\
\hline $\begin{array}{l}\text { In order to be a good medical practitioner I must have } \\
\text { good CS }\end{array}$ & 3 & 5 \\
\hline $\begin{array}{l}\text { Developing my CS is just as important as developing my } \\
\text { knowledge of medicine }\end{array}$ & 3 & 5 \\
\hline Learning CS will help me respect my patients & 3 & 4 \\
\hline Learning CS is interesting & 3 & 4 \\
\hline Learning CS will facilitate my team working skills & 3 & 5 \\
\hline $\begin{array}{l}\text { Learning CS will improve my ability to communicate with } \\
\text { patients }\end{array}$ & 3 & 5 \\
\hline Learning CS will help me respect my colleagues & 3 & 4 \\
\hline $\begin{array}{l}\text { I think it is useful to learn CS as a part of the medical } \\
\text { curriculum }\end{array}$ & 3 & 5 \\
\hline Composite CS scores* & 24 & 37 \\
\hline
\end{tabular}


Table 3 shows the median attitudes pre- and post-course towards ECE. There was a significant improvement in the attitude score $(p<0.05)$. Cronbach's alpha for calculating reliability was 0.807 for attitude scores towards ECE which indicated good reliability.

Table 4 shows the median attitudes pre- and post-course towards MLS. There was a significant improvement in the attitude score $(p<0.05)$. Cronbach's alpha for calculating reliability was 0.781 for attitude scores towards MLS which indicated good reliability.

In response to the close ended questions $92 \%$ $(n=100)$ affirmed that the course had helped allay their anxieties and given them confidence in facing challenges of the MBBS course, $83 \%$ $(n=90)$ affirmed that the course had helped familiarize them with their staff and seniors. All $(n=108)$ agreed that such courses should be conducted routinely for all fresh medical entrants.

Suggestions for improvement were: providing handouts of the sessions that could be preserved and referred to again later $(n=95$, $87 \%$ ), more question-answer sessions to solve queries ( $n=65,60 \%)$, incorporating additional sessions dealing with career guidance $(n=65$, $60 \%$ ) and financial support available for medical undergraduates $(n=50,40 \%)$.

Table 3: Median attitude scores towards ECE pre and post Foundation Course at SIMS \& RC, Mangalore, Karnataka, India August 2013

\begin{tabular}{lcc}
\hline $\begin{array}{l}\text { Statements to which response was generated on a } \\
\text { Likert's scale }\end{array}$ & Pedian score \\
\cline { 2 - 3 } & 2 & Post \\
\hline ECE increases my interest in clinical medicine & 5 \\
ECE helps me in better understanding of the upcoming & 2 & 4 \\
courses & 2 & 5 \\
ECE motivates me to work harder & 2 & 5 \\
ECE gives me an insight into community health concerns & 2 & 4 \\
ECE helps me to understand patient problems & 2 & 4 \\
ECE helps me to adapt better to my new environment & 3 & 5 \\
ECE helps me to get an understanding as regards & 3 \\
qualities required to succeed in clinical medicine & 32 \\
Composite ECE Scores & & 3 \\
${ }^{*} p<0.05$ ECE: Early Clinical Exposure, SIMS\&RC: Srinivas Institute of Medical Sciences and Research Centre
\end{tabular}

Table 4: Median Attitude Scores towards MLS pre and post Foundation Course at SIMS \& RC, Mangalore, Karnataka, India August 2013

\begin{tabular}{lcc}
\hline $\begin{array}{l}\text { Statements to which response was generated on a } \\
\text { Likert's scale }\end{array}$ & Pre & Post \\
\cline { 2 - 3 } MLS is interesting & 3 & 5 \\
MLS gives me an insight into medical databases & 3 & 5 \\
MLS is easy for me to understand as I have been doing net & 3 & 5 \\
surfing before & & 5 \\
MLS is essential to keep abreast of new developments in \\
$\begin{array}{l}\text { medical science } \\
\text { MLS will improve my ability to search for evidence in } \\
\text { medical science } \\
\begin{array}{l}\text { Evidence has an important role in medicine } \\
\text { Developing MLS skills is an important aspect of medical } \\
\text { education } \\
\text { Composite scores }\end{array}\end{array} \quad 3$ & 5 \\
\hline
\end{tabular}




\section{Discussion}

Foundation or orientation courses are conducted worldwide in colleges and universities to familiarize students to the faculty and the course and acclimatize them to the challenges of higher education. (Mittal, et al., 2014). Such programmes if unstructured (Hanon 2000), will not have the desired effect, and therefore research into this aspect of medical education would undoubtedly improve the quality of the courses. Appropriately prepared courses should prepare the new students for success.

Our Foundation Course was offered as a part of the medical curriculum in our institute. Although attendance was not made compulsory the students were encouraged to attend, stating that this would help them adapt to the needs of the MBBS course and to the institutional environment. Thus it was encouraging to note that not only did most of the students attend the course, a large number of the students agreed to participate in our study and give their feedback.

Our study was a first step in establishing how effective foundation courses could be designed and how some degree of universality could be brought about in the conduct of these courses for subsequent state or even nationwide adoption. The strengths of this study can be defined by the strength of the foundation course as perceived by the students. The improvement in the attitude scores of the students also provided evidence for the effectiveness of the course. The domains chosen for attitude comparison are domains which are of interest to any medical entrant irrespective of institute, state or country. Thus, this particular part of the study would be applicable universally and form an area of further research with the aim of improving the content and design of orientation and foundation courses worldwide.

The study had limitations. We did not have a validated questionnaire for testing student attitudes in all the domains that formed the basis of our study. We did not attempt any in depth interviews or focused group discussions with the students as a means of reinforcing the findings of our study. This was primarily due to lack of time. We did not obtain feedback of the foundation course from college faculty and management, important stakeholders in any program or course related to medical education. Feedback from parents or guardians would also have added to our knowledge of effective ways of designing a course for students who would now be leaving the safe comforts of their homes to live and study in a different environment. We did not research the perspectives and attitudes of the students towards the domains that were institution specific namely language, surrounding communities, alternative sources of medicine available in this area etc. These too could be taken as areas of research and improvement. Medical institutions in a specific geographical location or even state could work towards bringing about uniformity and affectivity in the content of these domains.

\section{Conclusions and future research}

The objective of our study was to describe the Foundation Course at our Institute and assess the participants' response to the selected domains as well as the overall effectiveness of the course with the belief that such studies would serve as a platform to design better courses. The course had a positive impact on the new entrants. It resulted in a significant improvement in their attitude scores in all the domains selected in the study.

In the future we aim to have focused group discussions and in depth interviews with students and faculty as a means of triangulation and to help improve the course. We aim to encourage students to maintain reflective learning diaries for targeted themes as is being done in some institutes (Pitkala \& Mantyranta, 2003; Pitkala \& Mantyranta, 2004). We aim to follow these students as they progress from their preclinical years to their para-clinical and clinical years, and get their perspectives about changes to increase the quality and relevance of the foundation course for future generations of medical undergraduates. This will also help us determine whether variants of this course would be beneficial at different transition phases of a medical undergraduate curriculum. An example would be a clinical orientation course just before they enter the hospital after passing their basic sciences (anatomy, physiology and biochemistry). First patient encounters have a strong emotional impact on students. Clinical reorientation courses can help students improve their skills when dealing with patients (Hayes et al., 2004; Sarikaya et al., 2006).

We also aim to study the faculty perspectives regarding such foundation courses and the practicality of having an extended course (2 months) as suggested by the $\mathrm{MCl}$. The next steps would be to invite faculty from neighbouring medical colleges to share their experiences and learn from them with the overall aim of having a well-designed, adequately implemented and universal foundation course for all our medical 
undergraduates across the state and country with some adjustments or additions pertaining to the local settings.

\section{Competing interests: None}

\section{Acknowledgements}

We would like to acknowledge all our institutional staff and students who helped us conduct the Foundation Course. We would like to especially thank Dr Swati, Dr Shreelaxmi Hegde, Dr Vishruta, Dr Aarthi Rao and Dr Sunitha for conducting the ice-breaking sessions which proved to be so popular among the new entrants. We would like to thank Dr Sameer, Dr Pawan, Dr Sunil, Dr Anitha and Dr Satish for conducting the various soft skills sessions.

\section{References}

Chumley, H., Olney, C., Usatine, R. \& Dobbie, A. (2005) A short transitional course can help medical students prepare for clinical learning, Family Medicine, 37, pp. 496-501.

Ellaway, R., Cooper, G., Al-Idrissi, T., Dube, T. \& Graves, L. (2014) Discourses of student orientation to medical education programs, Medical Education (Online), Available at http://dx.doi.org/10.3402/meo.v19.23714 [Accessed July 2014] .

Finkelstein, C., Brownstein, A., Scott, C. \& Lan. Y.L. (2007) Anxiety and stress reduction in medical education: an intervention, Medical Education, 41, pp. 258-264.

Hannon, F.B. (2000) A national medical education needs' assessment of intern and the development of an intern education and training programme, Medical Education, 34, 4, pp. 275-284.

Hayes, K., Feather, A. \& Hall, A. (2004) Anxiety in medical students: is preparation for full-time clinical attachments more dependent upon differences in maturity or on educational programmes for undergraduate and graduate entry students? Medical Education, 38, pp.11541163.

Hendelman, W. \& Byszewski, A. (2007) A national survey: medical professionalism in Canadian undergraduate programs, Canadian Conference for Medical Education, Victoria, BC; [Online] Available at: http://www.afmc.ca/pdf/ppt 2007_professionalism canada_en.ppt. [Accessed on July 2013].
Kiessling, C., Schubert, B., Scheffner, D. \& Burger, W. (2004) First year medical students' perceptions of stress and support: a comparison between reformed and traditional track curricula, Medical Education, 38, pp. 504-509.

Medical Council of India (2011) Vision 2015. New Delhi: Medical Council of India, [Online] Available at:http://www.mciindia. org/tools/ announcement / MCl_booklet. pdf. [Accessed July 2013].

Medical Council of India (2012) Regulations on Graduate Medical Education New Delhi: Medical Council of India, [Online] Available at:http://www.mciindia.org /tools/ announcement/ Revised_GME_2012. pdf. [Accessed July 2013].

Mittal, R., Mahajan, R. \& Mittal, N. (2013) Foundation programme: A student's perspective, International Journal of Applied and Basic Medical Research, 3, pp. $52-54$

Moffat, K., McConnachie, A., Ross, S. \& Morrison, J. (2004) First year medical students stress and coping in a problem based learning medical curriculum, Medical Education, 38, pp. 465-478.

Pandya H. (2009) Attitude of entry level medical students to a session on "Professionalism and Ethics" in foundation course, presented at the Association of Physicians of India Conference (APICON), Greater Noida, India; 2009 January $30^{\text {th }}$ - February $01^{\text {st }}, 2009$.

Pitkala, K.H. \& Mantyranta, T. (2003) Professional socialization revised: medical students' own conceptions related to adoption of the future physician's role--a qualitative study, Medical Teacher, 25, pp. 155-160.

Pitkälä, K.H., Mäntyranta, T. (2004) Feelings related to first patient experiences in medical school. A qualitative study on students' personal portfolios, Patient Education Counseling, 54, pp. 171-177.

Rosal, M.C., Ockene, I.S., Ockene, J.K., Barrett, S.V., Ma, Y. \& Hebert, J.R. (1997) A longitudinal study of students' depression at one medical school, Academic Medicine, 72, pp. 542-546.

Russell, P.C. (2002) The white coat ceremony: turning trust into entitlement, Teaching and Learning in Medicine, 14, pp. 56-59.

Sarikaya, O., Civaner, M. \& Kalaca, S. (2006) The anxieties of medical students related to clinical training, International Journal of Clinical Practice, 60 , pp.1414-1418. 